\title{
Current Status of Serum Insulin and C-Peptide Measurement in Clinical Laboratories: Experience from 94 Laboratories in China
}

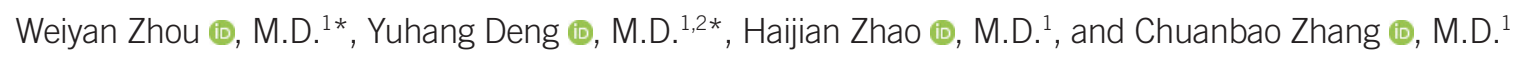 \\ ${ }^{1}$ National Center for Clinical Laboratories, Beijing Engineering Research Center of Laboratory Medicine, Beijing Hospital, National Center of Gerontology, \\ Institute of Geriatric Medicine, Chinese Academy of Medical Sciences, Beijing, P. R. China; ${ }^{2}$ Peking Union Medical College, Beijing, P. R. China
}

Background: Accurate measurements of serum insulin and C-peptide are needed for the therapy and classification of diabetes. This study investigated the status of serum insulin and C-peptide measurements in China by analyzing the results of five pooled serum samples measured in 94 laboratories.

Methods: Patient serum samples were pooled into five groups according to insulin and Cpeptide concentrations and measured in 94 laboratories using different measurement systems. The inter- and intra-laboratory \% CV as well as inter- and intra-measurement system \%CV were calculated to assess the status of insulin and C-peptide measurements. To verify whether the disagreement between laboratories was due to different calibrators, as reported in previous studies, one low-level and one high-level sample extracted from the five pooled serum samples were used to recalibrate clinical measurement systems.

Results: The mean intra-laboratory, intra-measurement system, inter-laboratory, and intermeasurement system \%CVs were $2.7 \%, 4.8 \%, 21.8 \%$, and $22.4 \%$, respectively, for insulin and $2.3 \%, 6.7 \%, 16.4 \%$, and $24.5 \%$, respectively, for C-peptide. The inter- and intralaboratory \%CVs for insulin decreased with increasing concentration. After recalibration with low- and high-level samples, the mean inter-measurement \%CV decreased from $22.4 \%$ to $17.2 \%$ for insulin and from $24.5 \%$ to $5.7 \%$ for C-peptide.

Conclusions: The intra-laboratory and intra-measurement system imprecision values are satisfactory for serum insulin and C-peptide measurements. However, the results from laboratories using different measurement systems were not comparable, and there is still much work needed to achieve the standardization or harmonization of serum insulin and C-peptide measurements.

Key Words: C-peptide, Insulin, Harmonization, Standardization, Diabetes mellitus
Received: August 23, 2021

Revision received: September 27, 2021

Accepted: January 24, 2022

\section{Corresponding author:}

Chuanbao Zhang, M.D.

National Center for Clinical Laboratories, Beijing Engineering Research Center of Laboratory Medicine, Beijing Hospital, National Center of Gerontology, Institute of Geriatric Medicine, Chinese Academy of Medical Sciences, No. 1 Dahua Road, Dongcheng District, Beijing 100730,

P. R. China

Tel: +86-010-58115059

Fax: +86-010-65132968

E-mail: cbzhang@nccl.org.cn

*These authors contributed equally to this work.

\section{(i) $\$$}

(c) Korean Society for Laboratory Medicine This is an Open Access article distributed under the terms of the Creative Commons Attribution Non-Commercial License (https://creativecommons.org/licenses/by-nc/4.0) which permits unrestricted non-commercial use, distribution, and reproduction in any medium, provided the original work is properly cited.

\section{INTRODUCTION}

The number of patients with diabetes mellitus has increased substantially during the past few decades and is projected to continue to increase in the future $[1,2]$. Accurate information about insulin secretion, insulin resistance, and residual beta-cell function is needed for the therapy and classification of diabetes.
Insulin and C-peptide measurements are the most frequently ordered laboratory tests to assess residual beta-cell function and insulin resistance for patients with diabetes [3, 4]. Therefore, it is pivotal to harmonize insulin and C-peptide measurements among clinical laboratories. Such harmonization will facilitate the integration of information from numerous studies as well as the establishment of practical clinical guidelines to be 
used in most clinical settings.

Despite the increasing relevance of insulin and C-peptide measurements, studies have reported discordance among results obtained from different laboratories and different measurement systems; thus, substantial effort has been made to improve their harmonization status [5-8]. In 1996, the American Diabetes Association found that insulin measurements from different laboratories were widely discordant [9]. In 2004, with the help of the National Institute of Diabetes and Digestive and Kidney Diseases of the United States, the European Association for the Study of Diabetes, the Center for Disease Control of the United States, and the International Federation of Clinical Chemistry and Laboratory Medicine, an American Diabetes Association workgroup was established to promote the comparability between insulin measurement results. In 2007, the working group reported improvement in the harmonization status of insulin measurements compared with that reported earlier [9, 10]. However, this report also indicated that insulin measurements were still far from thorough standardization. A series of studies conducted by Manley, et al. [8] and Van Houcke, et al. [11] demonstrated that the comparability among laboratories could be improved using individual or pooled serum samples whose target values were determined by isotope dilution mass spectrometry (IDMS) to calibrate routine methods, which could help improve the traceability of manufacturers' calibration systems to IDMS methods.

In 2002, the C-Peptide Standardization Committee sponsored by the National Institute of Diabetes and Digestive and Kidney Diseases in the United States was established to promote the standardization of C-peptide measurements. The committee conducted an international comparison of C-peptide measurements in 2007, demonstrating that the results from different laboratories were not comparable [12]. During the past few decades, considerable effort has been made to achieve harmonization between laboratories, which were comprehensively summarized by Little, et al. in 2017 [6] .

Since the most recent studies investigating the harmonization status of insulin and C-peptide measurements were conducted in 2007, there is an urgent need to determine whether there has been improvement $[8,12]$. To assess the current harmonization status of serum insulin and C-peptide measurement of clinical laboratories in China, we compared the results of five pooled serum samples measured in 94 laboratories. The interand intra-laboratory \%CVs as well as inter- and intra-measurement system \%CVs were calculated and compared. To verify whether the poor comparability between laboratories remains linked to the calibrators of measurement systems, as reported previously [6, 13, 14], low- and high-level serum samples were used to recalibrate results from different measurement systems, and the results before and after recalibration were compared.

\section{MATERIALS AND METHODS}

\section{Samples}

The set of five pooled serum samples were prepared from a large number of leftover samples collected from Beijing Hospital, Beijing, China, between August 2020 and January 2021. All samples were from patients undergoing insulin and C-peptide detections at Beijing Hospital clinical laboratory where the Siemens ADVIA Centaur XPT (Siemens Healthineers, Berlin, Germany) system was used. All samples were tested to ensure they did not react with anti-HIV antibodies, anti-hepatitis $C$ virus antibodies, and hepatitis B virus surface antigen. Patient serum samples with hemolysis, icterus, or lipemia were considered deviant and not included for analysis. The Ethics Committee of Beijing Hospital approved this study and exempted the need for obtaining informed consent (approval number 2018BJYYEC-019-01). Collected patient serum samples were first divided into five groups (202111: insulin $<0.06 \mathrm{nmol} / \mathrm{L}$ and C-peptide $<0.25$ nmol/L; 202112: insulin 0.10-0.30 nmol/L and C-peptide 0.50$0.70 \mathrm{nmol} / \mathrm{L} ; 202113$ : insulin $0.30-0.40 \mathrm{nmol} / \mathrm{L}$ and C-peptide 1.50-1.90 nmol/L; 202114: insulin 0.40-0.50 nmol/L and Cpeptide 2.00-2.30 nmol/L for C-peptide; and 202115: insulin $>0.50 \mathrm{nmol} / \mathrm{L}$ and $\mathrm{C}$-peptide $>3.00 \mathrm{nmol} / \mathrm{L}$ ) according to the primary results from Beijing Hospital. Samples in the same group were thawed, pooled overnight at $4^{\circ} \mathrm{C}$ on a magnetic stirring apparatus, and filtered using a vacuum pump (first with a $0.45-\mu \mathrm{m}$ filter membrane and then with a $0.22-\mu \mathrm{m}$ filter membrane). Each of the five pooled serum samples was split into aliquots of $0.5 \mathrm{~mL}$ in vials and stored at $-80^{\circ} \mathrm{C}$ until shipment on dry ice to the participating laboratories. To ensure the homogeneity of aliquots of each pooled serum sample, complete mixing of the five pooled serum samples was ensured during the process of aliquoting using a magnetic stirring apparatus.

\section{Analytical methods}

One hundred eighty laboratories across China, which used various measurement systems (Roche, Abbott, Siemens, Beckman, Mindray, and Snibe; Supplemental Data Table S1), signed up for this national investigation program. Given the limited aliquots of pooled serum samples, there was a demand to select a portion of the participating laboratories for subsequent measure- 
ments. The laboratories were first grouped according to their measurement systems to ensure a constant proportion of different systems used before and after the selection; the locations of selected laboratories were also chosen to be distributed as evenly possible across China. Ninety-four laboratories were ultimately selected. A registration form was provided to each selected laboratory requesting relevant information on reagents, calibrators, and measurement principles; other information, including the traceability of the measurement systems and the recommended reference interval, were provided by the manufacturers of the relevant measurement systems (Supplemental Data Table S1).

\section{Measurement protocol}

The five pooled serum samples with three replicates each (total of 15 aliquots) were distributed on dry ice to the laboratories and stored at $-80^{\circ} \mathrm{C}$ until measurement. The laboratories were instructed to measure one aliquot for each concentration two times a day at three specified days. All laboratory measurements were based on the protocols recommended by Chinese National Center for Clinical Laboratories for frozen serum samples. In brief, on the day of measurement, samples were let to stand at room temperature for approximately 20 minutes and mixed upside down 10 times. After reaching room temperature, each sample was measured twice consecutively. After converting the respective units into a standard unit ( $\mathrm{nmol} / \mathrm{L}$ ), each laboratory was requested to submit six values for each pooled serum sample before the given deadline for a total of 30 values for the five serum samples.

\section{Statistical analysis}

Data from laboratories that did not convert their units were removed prior to analysis. The six repeated values for each pooled serum sample from each laboratory were used to calculate the intra-laboratory imprecision (intra-laboratory \%CV). The interlaboratory imprecision (inter-laboratory \% CV) was calculated using the mean of the six repeated values for each laboratory. Laboratories were divided into seven groups according to the measurement system used: Roche, Abbott, Siemens, Beckman, Mindray, Snibe, and others (including laboratories without information of measurement systems). The mean of laboratories in the same group was used to calculate the inter-measurement system imprecision (inter-measurement system \%CV). The means of six repeated values of laboratories in the same group were used to calculate the intra-measurement system imprecision (intra-measurement system \%CV).
The desirable analytical performance specifications (APS) for imprecision (10.6\% for insulin, 8.3\% for C-peptide) applied in this study were based on biological variation data and on the Westgard website (https://www.westgard.com/biodatabase1. $\mathrm{htm}$ ) [15]. ANOVA was used to explore differences of inter-laboratory \%CVs between concentrations; differences were considered to be statistically significant at $P<0.05$.

To determine whether differences between measurement systems were correlated with the respective calibrators, two of the five pooled serum samples with the lowest and highest concentrations (202112 and 202115) were used to recalibrate the results of the other samples (202111, 202113, and 202114). The mean results of all measurement systems were set as the target values of the recalibration materials (202112 and 202115). The means of all laboratories using the same measurement system were regarded as the representative value of that measurement system. The target values as well as the representative values of samples 202112 and 202115 were used to draw the new standard curves for the six measurement systems. The recalibrated representative values of the six measurement systems for the other samples (202111, 202113, and 202114) were then calculated by placing the original representative values onto the new standard curve. The recalibrated representative values were used to calculate the recalibrated inter-measurement system \%CV, which was compared with that calculated before recalibration. All calculations were performed in Microsoft Excel 2016 (Microsoft Corporation, Redmond, Washington, USA), R language, and MedCalc statistical software 18.11.6-64-bit (Mariakerke, Belgium).

\section{RESULTS}

\section{Measurement systems used by the laboratories}

After excluding laboratories that did not provide measurements in the converted units, 91 and 88 laboratories reported complete results for insulin and C-peptide, respectively. All laboratories used homogeneous measurement systems (i.e., the instruments, reagents, and calibrators were produced by the same manufacturers). The top six measurement systems were from Roche, Siemens, Abbott, Beckman, Snibe, and Mindray, which are based on antigen-antibody reactions but use different immunological principles, and the recommended reference intervals for fasting serum insulin and C-peptide vary considerably (Supplemental Data Table S1). 
Intra- and inter-laboratory imprecision

The intra-laboratory \%CVs were acceptable, as 87/88 laboratories met the APS for C-peptide and 87/91 laboratories met the APS for insulin (Fig. 1, Table 1). The intra-laboratory \%CVs presented a decreasing trend with increasing insulin concentration (ANOVA: $P=0.0059 ; 202111$ vs. $202113 P=0.0255 ; 202111$ vs. $202115 P=0.0063$ ); however, no distinct trend was observed for C-peptide (ANOVA: $P=0.702$ ) (Fig. 1).

The large inter-laboratory \%CVs for insulin and C-peptide measurement indicated the unsatisfactory comparability among laboratories (Table 1). Larger inter-laboratory \%CVs were observed for sample 202111 for both insulin and C-peptide, suggesting worse comparability among laboratories when measuring samples with low concentrations of the target analyte.

\section{Differences among measurement systems}

The results of five pooled serum samples measured by various measurement systems are presented in Fig. 2 and Fig. 3. All intra-measurement system \%CVs met the APS of $10.6 \%$ for insulin and $8.3 \%$ for C-peptide. Intra-measurement system \%CVs were much smaller than inter-measurement system \%CVs for both analytes, indicating significant differences among measurements systems (Table 2). The worst comparability among measurement systems was observed for the low-concentration sample (202111) with an inter-measurement system \%CV of $58.28 \%$ for insulin and of 31.6\% for C-peptide (Table 2).

\section{Recalibration}

After recalibration, except for sample 202111 for insulin measurement, all inter-measurement system \%CVs met the APS for both analytes. This suggested that the source of discordance among different measurement systems was mainly derived from the valuation transfer and traceability systems (Table 3). Although the inter-measurement system \%CV of sample 202111
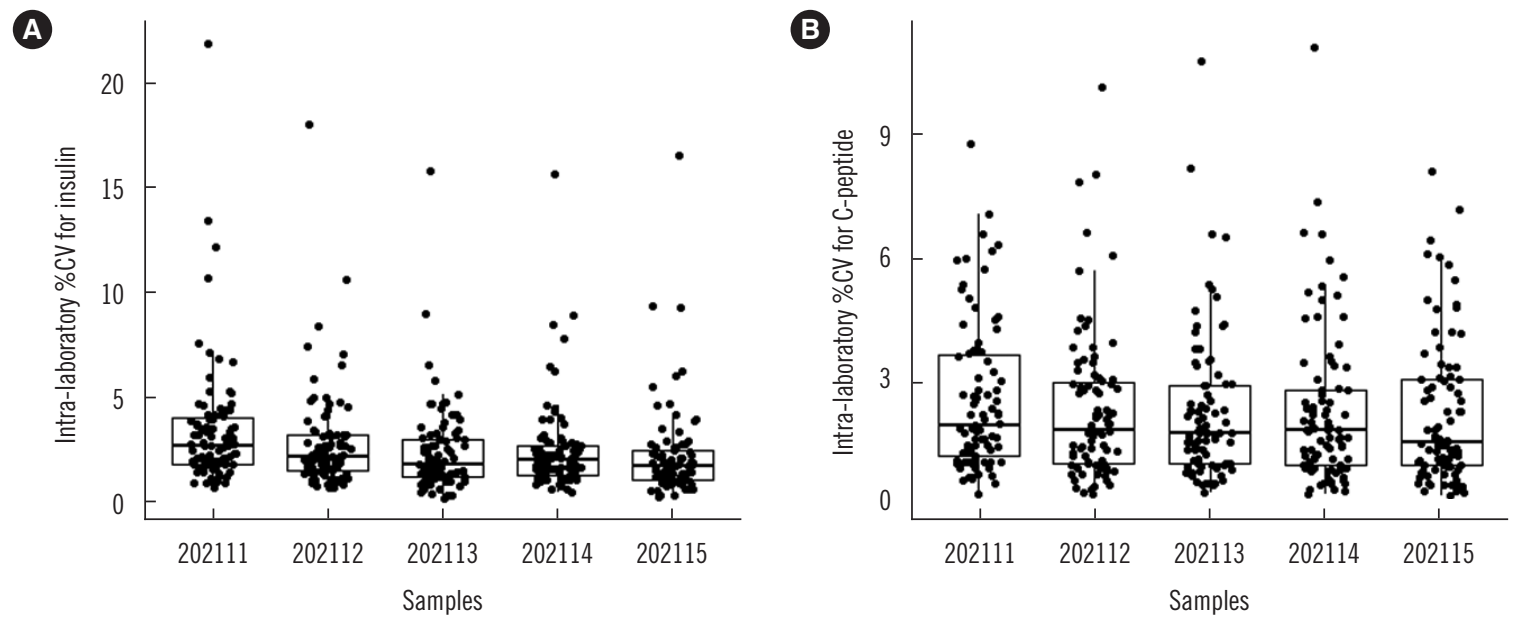

Fig. 1. Intra-laboratory \%CVs for insulin and C-peptide measurements. (A) Intra-laboratory \%CVs of insulin measurements, showing a decreasing trend with increasing concentration of insulin (ANOVA: $P=0.0059 ; 202111$ vs. $202113 P=0.0255 ; 202111$ vs. 202115 $P=0.0063$ ). (B) Intra-laboratory \%CVs of C-peptide measurements, with no significant trend observed (ANOVA: $P=0.702)$. The serum samples are shown in order of insulin and C-peptide concentration.

Table 1. Intra-laboratory and inter-laboratory \%CVs of insulin and C-peptide measurements

\begin{tabular}{|c|c|c|c|c|c|c|c|c|}
\hline \multirow{3}{*}{ Samples } & \multicolumn{4}{|c|}{ Insulin } & \multicolumn{4}{|c|}{ C-peptide } \\
\hline & \multirow{2}{*}{$\begin{array}{c}\text { Target } \\
\text { (nmol/L) }\end{array}$} & \multicolumn{2}{|c|}{ Intra-laboratory \%CV } & \multirow{2}{*}{$\begin{array}{c}\text { Inter-laboratory } \\
\% \text { CV }\end{array}$} & \multirow{2}{*}{$\begin{array}{l}\text { Target } \\
\text { (nmol/L) }\end{array}$} & \multicolumn{2}{|c|}{ Intra-laboratory \%CV } & \multirow{2}{*}{$\begin{array}{c}\text { Inter-laboratory } \\
\% \mathrm{CV}\end{array}$} \\
\hline & & Range & Mean & & & Range & Mean & \\
\hline 202111 & 0.071 & $0.7-21.8$ & 3.4 & 64.3 & 0.319 & $0.0-8.8$ & 2.5 & 21.8 \\
\hline 202112 & 0.123 & $0.7-18.0$ & 2.8 & 8.4 & 0.937 & $0.3-10.1$ & 2.3 & 17.4 \\
\hline 202113 & 0.357 & $0.2-15.7$ & 2.4 & 13.1 & 2.376 & $0.3-10.7$ & 2.3 & 14.8 \\
\hline 202114 & 0.386 & $0.5-15.6$ & 2.5 & 10.0 & 3.081 & $0.3-11.1$ & 2.3 & 14.4 \\
\hline 202115 & 0.932 & $0.3-16.5$ & 2.2 & 13.3 & 4.308 & $0.3-8.1$ & 2.2 & 13.6 \\
\hline
\end{tabular}

Abbreviations: Intra-lab, intra-laboratory; Inter-lab, inter-laboratory. 

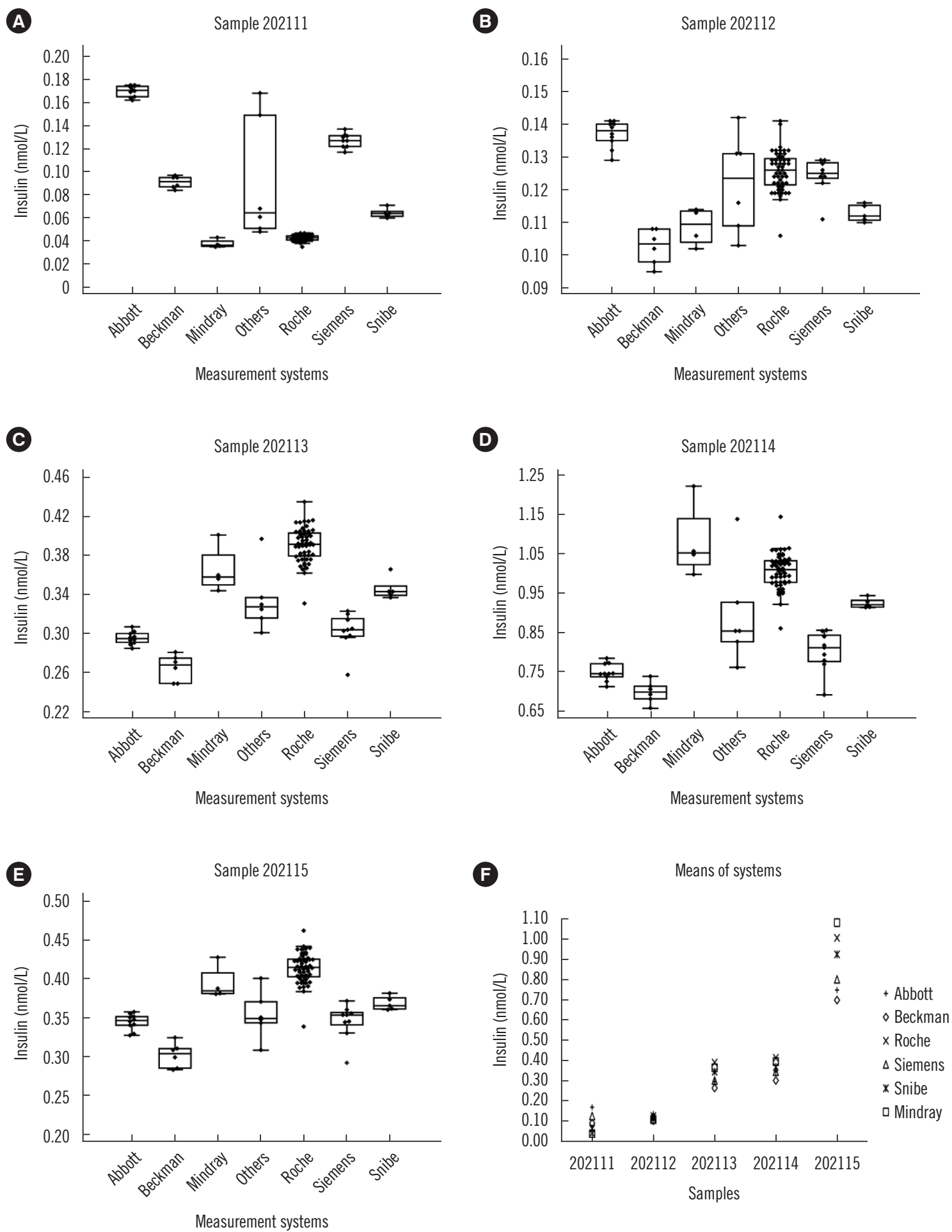

Fig. 2. Insulin measurement results obtained using different measurement systems for the five pooled samples (A-E). (F) Mean results for the measurement systems. The X-axis presents the five pooled samples and the Y-axis represents the mean value of laboratories using the same measurement system. Each symbol represents a different measurement system, and the serum samples are shown in order of insulin concentration. 

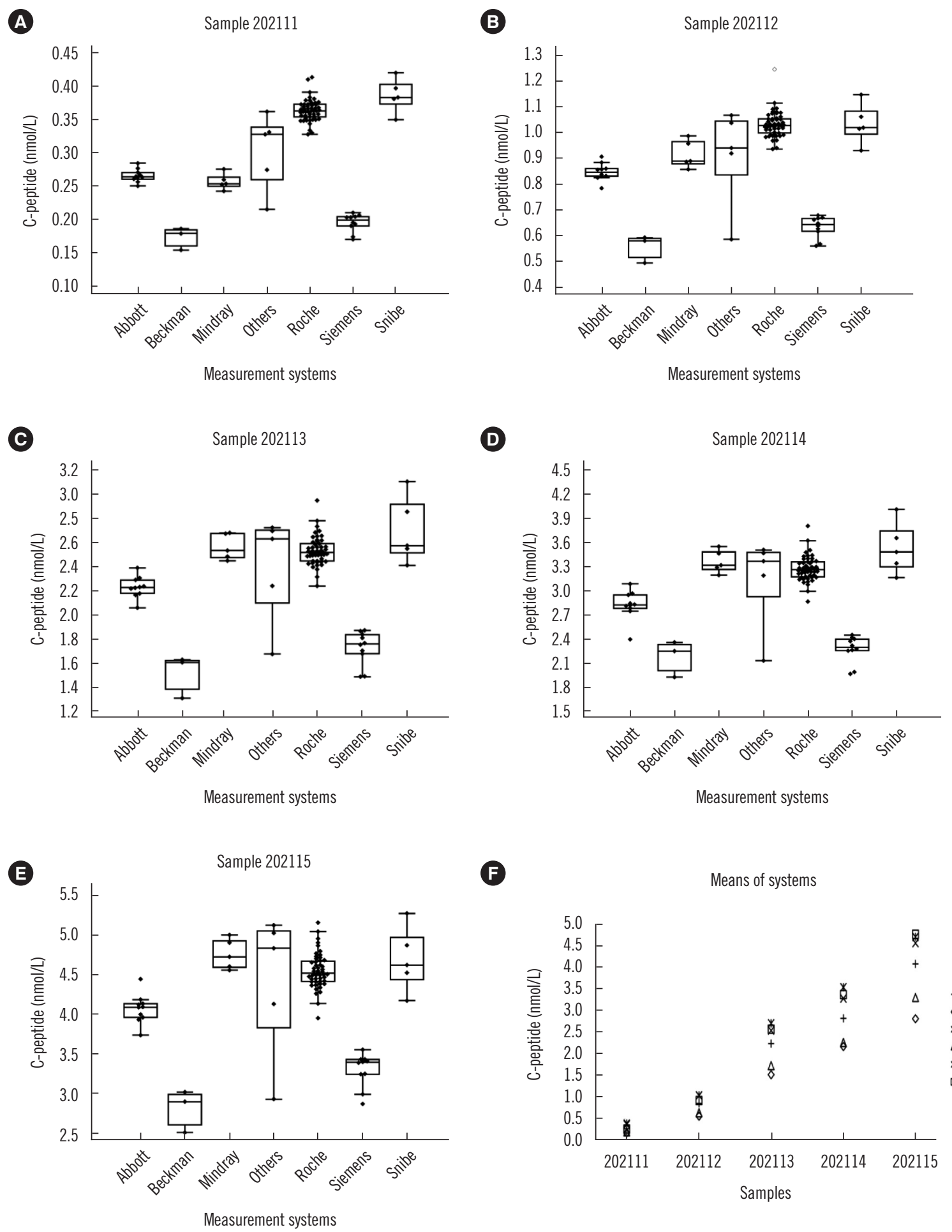

$\boldsymbol{F}$

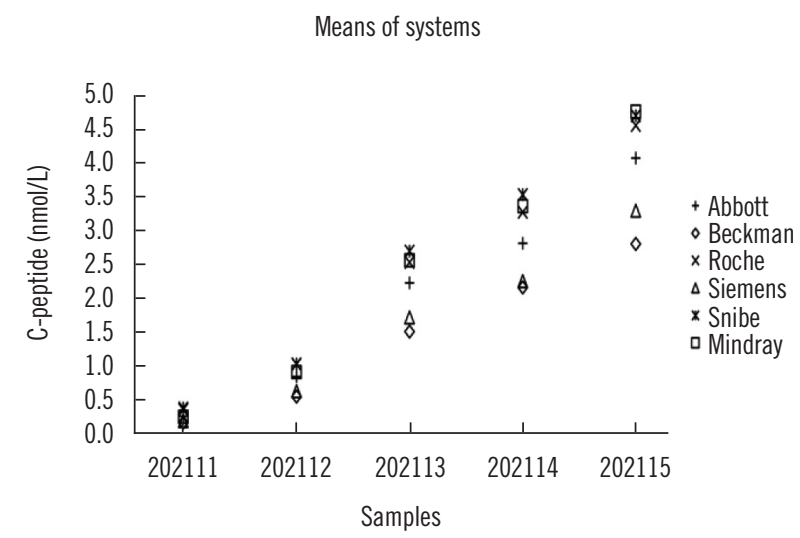

Fig. 3. C-peptide measurement results of different measurement systems for the five pooled samples (A-E). (F) Mean results of the measurement systems. The $\mathrm{X}$-axis shows the five pooled samples and the $\mathrm{Y}$-axis represents the mean value of laboratories using the same measurement system. Each symbol represents a different measurement system, and the serum samples are shown in order of C-peptide concentration. 
Table 2. Mean results for five pooled serum samples analyzed using different measurement systems, and the intra- and inter-MS \%CVs of insulin and C-peptide measurements

\begin{tabular}{|c|c|c|c|c|c|c|c|c|c|c|c|c|c|}
\hline \multirow{2}{*}{ Sample } & \multicolumn{6}{|c|}{ Representative values before recalibration ( $\mathrm{nmol} / \mathrm{L}$ ) } & \multicolumn{6}{|c|}{ Intra-MS \%CV } & \multirow{2}{*}{$\begin{array}{c}\text { Inter-MS } \\
\% C V\end{array}$} \\
\hline & Roche & Abbott & Siemens & Beckman & Snibe & Mindray & Roche & Abbott & Siemens & Beckman & Snibe & Mindray & \\
\hline \multicolumn{14}{|l|}{ Insulin } \\
\hline 202111 & 0.043 & 0.170 & 0.127 & 0.091 & 0.064 & 0.038 & 5.6 & 2.8 & 4.9 & 6.2 & 7.5 & 8.8 & 58.3 \\
\hline 202112 & 0.126 & 0.137 & 0.124 & 0.102 & 0.113 & 0.109 & 4.8 & 2.9 & 4.3 & 5.1 & 2.4 & 5.2 & 10.7 \\
\hline 202113 & 0.391 & 0.295 & 0.302 & 0.265 & 0.346 & 0.365 & 4.6 & 2.2 & 6.3 & 5.0 & 3.8 & 6.7 & 14.5 \\
\hline 202114 & 0.414 & 0.345 & 0.346 & 0.302 & 0.369 & 0.395 & 4.7 & 2.9 & 6.6 & 5.2 & 2.8 & 5.7 & 11.0 \\
\hline 202115 & 1.006 & 0.749 & 0.802 & 0.699 & 0.924 & 1.081 & 4.4 & 2.9 & 6.4 & 4.0 & 1.4 & 9.0 & 17.3 \\
\hline \multicolumn{14}{|l|}{ C-peptide } \\
\hline 202111 & 0.363 & 0.265 & 0.195 & 0.173 & 0.385 & 0.256 & 4.5 & 3.7 & 6.9 & 9.6 & 6.7 & 4.7 & 31.6 \\
\hline 202112 & 1.031 & 0.847 & 0.634 & 0.555 & 1.034 & 0.915 & 4.8 & 3.9 & 6.5 & 9.6 & 7.6 & 5.9 & 24.1 \\
\hline 202113 & 2.529 & 2.227 & 1.723 & 1.511 & 2.696 & 2.562 & 4.7 & 4.0 & 8.2 & 11.7 & 10.4 & 4.2 & 22.1 \\
\hline 202114 & 3.270 & 2.813 & 2.255 & 2.161 & 3.530 & 3.359 & 4.7 & 6.5 & 7.5 & 10.5 & 9.3 & 4.3 & 20.2 \\
\hline 202115 & 4.546 & 4.066 & 3.293 & 2.804 & 4.688 & 4.755 & 4.8 & 4.6 & 6.5 & 9.5 & 8.7 & 4.0 & 20.1 \\
\hline
\end{tabular}

Abbreviation: MS, measurement systems.

Table 3. Differences between measurement systems after recalibration

\begin{tabular}{|c|c|c|c|c|c|c|c|}
\hline \multirow{2}{*}{ Samples } & \multicolumn{6}{|c|}{ Representative values after recalibration ( $\mathrm{nmol} / \mathrm{L}$ ) } & \multirow{2}{*}{$\begin{array}{c}\text { Inter-MS \%CV } \\
\text { (after recalibration) }\end{array}$} \\
\hline & Roche & Abbott & Siemens & Beckman & Snibe & Mindray & \\
\hline \multicolumn{8}{|l|}{ Insulin } \\
\hline 202111 & 0.047 & 0.159 & 0.122 & 0.104 & 0.073 & 0.063 & 44.1 \\
\hline 202113 & 0.346 & 0.315 & 0.318 & 0.325 & 0.336 & 0.319 & 3.8 \\
\hline 202114 & 0.367 & 0.376 & 0.367 & 0.373 & 0.358 & 0.342 & 3.6 \\
\hline \multicolumn{8}{|l|}{ C-peptide } \\
\hline 202111 & 0.230 & 0.260 & 0.310 & 0.294 & 0.269 & 0.289 & 10.4 \\
\hline 202113 & 2.195 & 2.204 & 2.142 & 2.191 & 2.287 & 2.204 & 2.1 \\
\hline 202114 & 2.867 & 2.785 & 2.781 & 3.113 & 3.015 & 2.867 & 4.6 \\
\hline
\end{tabular}

Abbreviation: MS, measurement systems.

for insulin decreased from $58.28 \%$ to $44.1 \%$, it still did not meet the APS of $10.6 \%$.

\section{DISCUSSION}

On the basis of repeated results of five pooled serum samples from 94 laboratories, most intra-laboratory \%CVs met the APS requirements for both analytes, demonstrating the generally good intra-laboratory precision for insulin and C-peptide measurements in clinical laboratories. However, the insulin and Cpeptide measurements from different laboratories were not comparable, with inter-laboratory \%CVs ranging from $8.4 \%$ to $64.3 \%$ for insulin and from $13.6 \%$ to $21.8 \%$ for C-peptide. The intra- and inter-laboratory \%CVs increased with decreasing in- sulin concentration.

Accurate measurement of insulin at low concentration is clinically important for assessment of remaining beta-cell secretory function in type 2 diabetes as well as for assessing the insulin resistance of obese and non-obese patients. The obvious discordance among laboratories at low concentrations may result in contradictory testing interpretations. Similar to insulin, samples with a low C-peptide concentration had much higher interlaboratory \%CVs than those of samples with higher concentrations. We hypothesized that cross-reactions caused by various interferents such as pro-insulin or the metabolites of C-peptide would impact the comparability among different laboratories and measurement systems. Disparate degrees of cross-reactions were often observed for various measurement systems 
due to their different specificities, resulting in discordance between results from laboratories using different measurement procedures for the same set of samples, especially for samples with low concentrations of C-peptide.

This study found good comparability among laboratories using the same measurement systems for measurements of insulin and C-peptide with respective mean intra-measurement systems $\% \mathrm{CV}$ of $4.8 \%$ and $6.6 \%$. However, the results of different measurement systems were not comparable, with inter-measurement system \%CVs ranging from $10.7 \%$ to $58.3 \%$ for insulin and from $20.1 \%$ to $31.6 \%$ for C-peptide.

Although almost all of the manufacturers of the measurement systems included in this study claimed that their calibrators traced to the same WHO international reference reagents (WHO IRR 84/510 for C-peptide and 66/304 for insulin, which are both pure substances), except for Beckman whose calibrator for C-peptide traced to the WHO's first international standard $13 / 146$, the comparability among different measurement systems was not satisfactory. A likely explanation is that, as polypeptides, C-peptide and insulin may behave differently in pure solution than in a sample-matrix solution. The first international standard for human C-peptide (WHO ISR 13/146) and its international reference reagent (WHO IRR84/510) were reported to be incommutable for some measurement systems [12, 16]. Comparability of $\mathrm{C}$-peptide and insulin measurements between laboratories and measurement systems was effectively improved using one low-level and one high-level pooled sample to recalibrate clinical measurement systems, as reported previously [13, 14].

Much work is still needed to achieve standardization of Cpeptide and insulin measurements. For C-peptide, reference procedures and primary reference materials are listed in the Joint Committee for Traceability in Laboratory Medicine (JCTLM) dataset [17-19]. However, no commercially qualified secondary calibrators (usually sample matrix) are listed in the JCTLM dataset. Using serum samples assigned by a reference measurement procedure to calibrate clinical methods was corroborated as an effective approach to promote comparability among laboratories [14]. The provision of patient serum samples to manufacturers according to a reference measurement procedure is an alternative acceptable mechanism to trace the results of each measurement system to the reference measurement procedure and the conversion to SI units [6]. Recently, the C-peptide Standardization Committee organized the "C-Peptide Standardization Manufacturer Meeting" [20], including C-peptide Standardization Committee members, manufacturer represen- tatives, and other experts in clinical laboratory medicine. The Cpeptide Standardization Committee recommended that manufacturers use pooled serum or single donor samples whose target values determined by the reference measurement procedure to recalibrate their measurement systems for C-peptide. The committee and manufacturers are actively working to overcome the many hurdles in recalibration of patient samples according to a reference measurement procedure. This initiative will greatly improve the standardization status of C-peptide, which is expected to be achieved in the near future.

For insulin, no reference measurement procedure and reference materials are listed in the JCTLM dataset. To improve the harmonization and standardization of insulin measurement, the unbroken traceability chain, including the reference laboratory, reference measurement procedure, reference measurement service, and qualified secondary calibrators, should be developed. Another recommended approach to calibrate clinical measurement procedures is to use patient-derived secondary reference materials such as pooled or single-donor serum or plasma with values determined by higher-order measurement procedures such as isotope diluent liquid-phase tandem mass spectrometry (ID-LC-MS/MS) [14, 21].

External quality assessment (EQA) programs can provide valuable information about inter-laboratory imprecision, enabling the assessment and monitoring of the comparability among laboratories. However, the EQA materials for C-peptide and insulin in China are non-patient-derived lyophilized powders with unknown commutability, making it hard to compare and improve the between-method variations found in the EQA program. Since the commutability of patient-derived pooled serum samples is much better than that of non-patient-derived lyophilized powder, we used pooled serum samples in this study, as a more accurate method to recognize discordance among laboratories.

Despite the decrease in the inter-measurement system \%CV of sample 202111 for insulin from $58.3 \%$ to $44.1 \%$ after recalibration, it still did not meet the APS specification of $10.6 \%$, suggesting an influence other than traceability to explain the large inter-measurement system \%CV for samples with a low concentration of insulin. This high variability might also be associated with instrumental discrepancy such as the poor specificity and sensitivity of the measurement systems for low-concentration measurements. Exogenous insulin and insulin analogs are commonly employed treatments for patients with diabetes. However, different immunoassays from different manufacturers usually use different anti-insulin antibodies, which may differentially combine with exogenous insulin and insulin analogs. Because 
all of the serum samples in this study were collected from patients who might be treated with various types of exogenous insulin and insulin analogs, sample 202111 might have contained a matrix similar to an insulin analog and/or exogenous insulin, which may have impacted the insulin measurement and contributed to the discordance among results from different measurement systems.

There are some limitations to our study. First, despite collection of a large number of measurement results from 94 laboratories, the small sample sizes limited our analysis; for example, only two of five pooled serum samples were used to recalibrate the remaining three samples, which may be insufficiently representative. Second, to reflect the true proportion of each manufacturer in Chinese hospitals, we attempted to maintain the proportions of different measurement systems in the 94 selected laboratories before and after the selection. However, some systems were only used in few laboratories (Supplemental Data Table 1 ), and our results may not be sufficiently representative of this fact.

In conclusion, this study provides reliable data about laboratory performance as well as the standardization and harmonization status for serum insulin and C-peptide measurements. These data may provide support for laboratories to choose appropriate measurement systems to improve performance and can guide clinicians to better interpret the measurement results of serum insulin and C-peptide. We also demonstrated that commutable serum samples used as calibrators were effective in improving the comparability of serum C-peptide and insulin measurements obtained from different laboratories and measurement systems, as reported previously [6, 13, 14].

\section{ACKNOWLEDGMENTS}

Not applicable.

\section{AUTHOR CONTRIBUTIONS}

Zhou W wrote the manuscript, Deng Y performed the experiments and analyzed the data. Zhao $\mathrm{H}$ and Zhang $\mathrm{C}$ provided the idea for the study.

\section{CONFLICTS OF INTEREST}

No potential conflicts of interest relevant to this article are reported.

\section{RESEARCH FUNDING}

This study was supported by grants from the Beijing Natural Science Foundation (No. 7212087).

\section{ORCID}

$\begin{array}{ll}\text { Weiyan Zhou } & \text { https://orcid.org/0000-0003-4174-6047 } \\ \text { Yuhang Deng } & \text { https://orcid.org/0000-0003-4910-0267 } \\ \text { Haijian Zhao } & \text { https://orcid.org/0000-0002-7850-7827 } \\ \text { Chuanbao Zhang } & \text { https://orcid.org/0000-0003-0754-7511 }\end{array}$

\section{REFERENCES}

1. Zimmet P, Alberti KG, Magliano DJ, Bennett PH. Diabetes mellitus statistics on prevalence and mortality: facts and fallacies. Nat Rev Endocrinol 2016;12:616-22

2. Guariguata L, Whiting DR, Hambleton I, Beagley J, Linnenkamp U, Shaw JE. Global estimates of diabetes prevalence for 2013 and projections for 2035. Diabetes Res Clin Pract 2014;103:137-49.

3. Leighton E, Sainsbury CA, Jones GC. A practical review of C-peptide testing in diabetes. Diabetes Ther 2017;8:475-87.

4. Jones AG and Hattersley AT. The clinical utility of C-peptide measurement in the care of patients with diabetes. Diabet Med 2013;30:80317

5. Hörber S, Achenbach P, Schleicher E, Peter A. Harmonization of immunoassays for biomarkers in diabetes mellitus. Biotechnol Adv 2020;39: 107359.

6. Little RR, Wielgosz RI, Josephs R, Kinumi T, Takatsu A, Li H, et al. Implementing a reference measurement system for C-peptide: successes and lessons learned. Clin Chem 2017:63:1447-56.

7. Staten MA, Stern MP, Miller WG, Steffes MW, Campbell SE; Insulin Standardization Workgroup. Insulin assay standardization: leading to measures of insulin sensitivity and secretion for practical clinical care. Diabetes Care 2010;33:205-6.

8. Manley SE, Stratton IM, Clark PM, Luzio SD. Comparison of 11 human insulin assays: implications for clinical investigation and research. Clin Chem 2007:53:922-32.

9. Robbins DC, Andersen L, Bowsher R, Chance R, Dinesen B, Frank B, et al. Report of the American Diabetes Association's Task Force on standardization of the insulin assay. Diabetes 1996;45:242-56.

10. Marcovina S, Bowsher RR, Miller WG, Staten M, Myers G, Caudill SP, et al. Standardization of insulin immunoassays: report of the American Diabetes Association Workgroup. Clin Chem 2007;53:711-6.

11. Van Houcke SK, Van Aelst S, Van Uytfanghe K, Thienpont LM. Harmonization of immunoassays to the all-procedure trimmed mean-proof of concept by use of data from the insulin standardization project. Clin Chem Lab Med 2013;51:e103-5.

12. Wiedmeyer HM, Polonsky KS, Myers GL, Little RR, Greenbaum CJ, Goldstein $\mathrm{DE}$, et al. International comparison of $\mathrm{C}$-peptide measurements. Clin Chem 2007;53:784-7.

13. Miller WG, Thienpont LM, Van Uytfanghe K, Clark PM, Lindstedt P, Nilsson $\mathrm{G}$, et al. Toward standardization of insulin immunoassays. Clin Chem 2009;55:1011-8

14. Little RR, Rohlfing CL, Tennill AL, Madsen RW, Polonsky KS, Myers GL, 


\section{Zhou W, et al.}

et al. Standardization of C-peptide measurements. Clin Chem 2008;54: 1023-6.

15. Ricós C, Alvarez V, Cava F, García-Lario JV, Hernández A, Jiménez CV, et al. Current databases on biological variation: pros, cons and progress. Scand J Clin Lab Invest 1999;59:491-500.

16. Moore M, Dougall T, Ferguson J, Rigsby P, Burns C. Preparation, calibration and evaluation of the First International Standard for human Cpeptide. Clin Chem Lab Med 2017;55:1224-33.

17. Kinumi T, Mizuno R, Takatsu A. Quantification of serum C-peptide by isotope-dilution liquid chromatography-tandem mass spectrometry: enhanced detection using chemical modification and immunoaffinity purification. J Chromatogr B Analyt Technol Biomed Life Sci 2014;953954:138-42.

18. Kinumi T, Goto M, Eyama S, Kato M, Kasama T, Takatsu A. Develop- ment of SI-traceable C-peptide certified reference material NMIJ CRM 6901-a using isotope-dilution mass spectrometry-based amino acid analyses. Anal Bioanal Chem 2012;404:13-21.

19. Stoyanov AV, Rohlfing CL, Connolly S, Roberts ML, Nauser CL, Little RR. Use of cation exchange chromatography for human C-peptide isotope dilution-mass spectrometric assay. J Chromatogr A 2011;1218: 9244-9.

20. Little RR, 2021 C-Peptide Standardization Manufacturer Meeting Minutes, http://cpeptide.org/assets/cpeptide2021.pdf (Updated on Jan 2022).

21. Rodríguez-Cabaleiro D, Van Uytfanghe K, Stove V, Fiers T, Thienpont LM. Pilot study for the standardization of insulin immunoassays with isotope dilution liquid chromatography/tandem mass spectrometry. Clin Chem 2007;53:1462-9. 
Supplemental Data Table S1. Details of the measurement systems used by the participating laboratories

\begin{tabular}{|c|c|c|c|c|c|c|}
\hline Manufacturers & Roche & Abbott & Siemens & Beckman & Snibe* & Mindray* \\
\hline Name/model & $\begin{array}{c}\text { Roche Cobas e601/ } \\
\text { e602/e801/E411 }\end{array}$ & $\begin{array}{l}\text { Abbott Architect } \\
\text { i2000sr/i2000/ } \\
\text { i1000sr }\end{array}$ & $\begin{array}{l}\text { Siemens Advia } \\
\text { Centaur CP/XP }\end{array}$ & $\begin{array}{c}\text { Beckman DXI 600/ } \\
\text { DXI } 800\end{array}$ & $\begin{array}{l}\text { Maglumi } \\
\text { /1000/1000Plus } \\
\text { /2000/2000plus }\end{array}$ & $\begin{array}{l}\text { CL6000i/CL6200i/ } \\
\text { CL2000i CL1000i }\end{array}$ \\
\hline Country/city & Switzerland/ Basel & USA/Chicago & Germany/Berlin & USA/Brea & China/Shenzhen & China/Shenzhen \\
\hline Principle & $\begin{array}{l}\text { Electroluminescence } \\
\text { immunoassay }\end{array}$ & $\begin{array}{c}\text { Microparticle } \\
\text { chemiluminescence } \\
\text { immunoassay }\end{array}$ & $\begin{array}{l}\text { Acridine esterification } \\
\text { chemiluminescence } \\
\text { immunoassay }\end{array}$ & $\begin{array}{c}\text { Microparticle } \\
\text { chemiluminescence } \\
\text { immunoassay }\end{array}$ & $\begin{array}{c}\text { Chemiluminescence } \\
\text { immunoassay }\end{array}$ & $\begin{array}{c}\text { AMPPD-labeled } \\
\text { microparticle } \\
\text { chemiluminescence } \\
\text { immunoassay }\end{array}$ \\
\hline \multicolumn{7}{|l|}{$N(\%)$} \\
\hline Insulin & $52(57)$ & $10(11)$ & $9(10)$ & $6(6)$ & $5(5)$ & $4(4)$ \\
\hline C-peptide & $50(57)$ & $10(11)$ & $10(11)$ & $3(3)$ & $5(6)$ & $5(6)$ \\
\hline \multicolumn{7}{|c|}{ Traceability of calibrator } \\
\hline Insulin & WHO IRR 66/304 & WHO IRP 66/304 & WHO IRP 66/304 & WHO IRP 66/304 & WHO IRP 66/304 & WHO IRP 66/304 \\
\hline C-peptide & WHO IRP 84/510 & WHO IRP 84/510 & WH0 IRP84/510 & WHO ISR 13/146 & WHO IRP 84/510 & WH0 IRP 84/510 \\
\hline \multicolumn{7}{|c|}{ Manufacturers recommended RI (nmol/L) } \\
\hline Insulin & $0.017-0.173$ & $\mathrm{~N} / \mathrm{A}$ & $0.021-0.175$ & $0.013-0.161$ & $0.028-0.153$ & $0.015-0.172$ \\
\hline C-peptide & $0.370-1.470$ & $0.260-1.730$ & $0.160-1.280$ & $0.207-0.913$ & $0.100-1.243$ & $0.330-1.600$ \\
\hline
\end{tabular}

${ }^{*}$ Chinese manufacturer.

Abbreviations: AMPPD, 3-(2'-spiroadamantyl)-4-methoxy-4-(3'-phosphoryloxy)-phenyl-1,2-dioxetane; N/A, not applicable; RI, reference interval; IRR, international reference reagent; IRP, international reference preparation; ISR, international standard reagent. 